\title{
A abordagem acerca da cultura indígena no ensino fundamental no município de Araguari/MG
}

DOI: 10.47224/revista master.v6i11.157

\author{
Danilo Faria de Moura \\ Maria Luiza de Borba Alves \\ Ana Clara Aparecida de Ávila \\ Francisca Eulânia de Caldas Silva Rodrigues \\ Geovana da Cunha Machado \\ Isabella Beatriz de Melo Santos \\ Priscila Renata Vieira \\ Rafaela Borges Calixto \\ Rebeca Rayssa Ferreira
}

e-mail: danilofmoura@yahoo.com.br

\section{Resumo}

Este estudo levanta apontamentos a respeito da cultura indígena nas escolas. A escolha do tema se deu em função da aplicação da lei de 11.649/08 que propõe a inclusão nos currículos acadêmicos a obrigatoriedade do ensino da história e cultura dos povos indígenas, tendo em vista que esta tem sido cumprida muito timidamente pelas instituições de ensino. Objetiva-se possibilitar uma abordagem crítica acerca da construção do conhecimento histórico e das limitações de sua compreensão. O estudo foi realizado por meio da metodologia do Arco de Maguerez, seguindo as etapas de observação da realidade, pontos-chave, teorização, hipótese de solução e aplicação na realidade, fazendo-se uso de uma pesquisa bibliográfica para embasamento. Elaborou-se um questionário informativo, destinado a várias professoras da rede pública e privada para observação dos aspectos presentes nas rotinas escolares, visto que, em virtude da pandemia da Covid-19, não se fez possível a observação presencial. Compreende-se que o ensino deve ser compreendido como um processo de instrumentalização dos sujeitos, que os convida a desenvolver o raciocínio histórico e um enredo repetitivo constituído.

Palavras-chave: Educação étnico-racial, Cultura indígena, Valorização étnica-racial.

\begin{abstract}
This study raises notes about indigenous culture in schools. The selection of the theme was thanks to the appliance of the law of 11.649/08 which proposes the inclusion in academic curricula of the mandatory teaching of the history and culture of indigenous peoples, considering that this has been very timidly followed by educational institutions. It aims to enable a critical approach to the development of historical knowledge and therefore the limitations of its understanding. The study was administered using the Arco de Maguerez methodology, following the steps of observation of reality, key points, theorization, solution hypothesis and application actually, making use of a bibliographic research for foundation. An informative questionnaire was designed for several public and personal teachers to watch the aspects present in class routines, since, thanks to the Covid-19 pandemic, face-to-face observation wasn't possible. It's understood that teaching must be understood as a process of instrumentalization of subjects, which invites them to develop historical reasoning and a repetitive plot formed.
\end{abstract}

Keywords: $\quad$ Ethnic-racial education, Indigenous culture, Ethnic-racial valorization. 


\section{INTRODUÇÃO}

A educação cultural, presente no cotidiano escolar, é muito insuficiente quando aplicada à matriz curricular da educação infantil, deixando evidente uma considerável dívida histórica, com os povos indígenas, africanos e afrodescendentes. Após inúmeros anos de lutas pela igualdade, essa variável passou-se a ser considerada uma importante diversidade étnico cultural nos currículos escolares. Porém, muitas vezes esta vem sendo aplicada apenas teoricamente, não se a devida atenção e importância nas práticas do contexto escolar. É indispensável ao professor ser o mediador do conhecimento na relação de ensino-aprendizagem, no entanto o grande diferencial está no método em que o docente vai abordar a temática.

A Lei 11.645/2008 apresenta relevantes alterações na Lei 9.394/1996, anteriormente modificada pela Lei $10.639 / 2003$, a qual estabelece as diretrizes e bases da educação nacional que indicam a emergente necessidade de incluir no currículo oficial da rede de ensino a obrigatoriedade da temática história e cultura africana, afro-brasileira e indígena. Essas mudanças implicam na necessidade de abordar a temática em questão no ensino de todas as disciplinas do currículo do ensino fundamental, que inclui o ensino fundamental e médio. (GOULART, 2013, p. 6)

Ressalta-se a importância da adoção de novas metodologias no ensino do tema, utilizando recursos distintos e inseridos nas disciplinas de forma significativa. Observando-se no cotidiano das escolas que muitas ainda ignoram a relevância da abordagem, não atribuindo a possibilidade de agregar um conhecimento maior em suas práticas de aprendizagem.

Por meio de uma revisão de literatura evidenciou a preocupação por parte de pesquisadores e estudiosos referentes à questão indígena relacionadas ao preparo dos professores para discutir o tema, bem como as condições existentes nas escolas, que na maioria das vezes não são adequadas para fazer abordagens que integrem sua prática à vida social. Segundo alguns pesquisadores a formação docente para tratar as relações étnicoraciais ainda está muito aquém do necessário para contribuir efetivamente com a construção de uma sociedade mais equânime, reforçando que somente as leis vigentes não possibilitarão que os professores se posicionem devidamente como agentes fomentadores de mudanças, pois é preciso que o Estado viabilize um ambiente propício ao ensino da cultura indígena. (SILVA; OLIVEIRA, 2017, p. 154)

Faz-se necessário um ambiente adequado para uma aprendizagem mais eficaz em que a história sobre etnias seja desenvolvida. As intuições, sejam elas particulares ou privadas, precisam programar e aplicar práticas não apenas em datas comemorativas, organizando um calendário anual para que a temática esteja presente na escola decorrer de todo o ano.

O docente deve se colocar como mediador do conhecimento e apresentar de forma clara as questões relacionadas às culturas do país vislumbrando e fomentando os aspectos históricos em busca de balizamento do conhecimento e entendimento dos marcadores sociais que impossibilitam que a igualdade social ocorra.

O presente artigo é resultante das atividades desenvolvidas no Curso de Pedagogia, no componente curricular "Projeto Integrador VII Educação das Relações Étnico-raciais e história e cultura afro-brasileira, africana e indígena", do sexto e sétimos períodos, do primeiro semestre de 2020 .

As pesquisas que compõe este artigo foram desenvolvidas por meio da Metodologia da Problematização com o Arco de Maguerez norteadas pela seguinte temática: a abordagem da cultura afro-brasileira no ensino fundamental das escolas públicas na cidade de Araguari/MG. Utilizouse de um questionário respondido por professoras para a observação da realidade e de revisão bibliográfica para o embasamento teórico dos assuntos apresentados.

“(...) a nossa terra não era habitada apenas por um povo, mas por vários. Cada um com sua cultura. Cada um ocupando uma parte de nossa terra" (FREIRE, 1979, p. 23). Na maioria das vezes, ou em quase todas elas, observa-se a dificuldade enfrentada pelos docentes em implementar a temática étnico-racial no cotidiano escolar, sendo abordados superficialmente em datas comemorativas, havendo relatos que justificam essa lacuna em virtude da falta de tempo, recursos, preparo entre outros. Busca-se fomentar caminhos para que ocorra uma mudança nessa questão, sendo um dos caminhos estabelecer o aprofundamento dessa temática, levando em consideração a cultura 
e a verdadeira história do país, para assim contribuir com a valorização desses povos.

Os professores devem abordar o tema em sala de aula, aguçando a curiosidade dos alunos em explorar a diversidade de assuntos na perspectiva indígena. Sendo assim, devem procurar se aprimorar mais sobre esses povos e suas culturas, colocando em pauta com maior frequência, intensidade, propriedade e aprofundamento.

O objetivo geral desse artigo é investigar sobre a aplicação das diretrizes da LBD (Lei de Diretrizes e Bases da Educação), referentes à inclusão da temática História e Cultura Indígena nos currículos do ensino fundamental.

Os objetivos específicos compreendem as práticas pedagógicas utilizadas pelos docentes ao pontuarem essa temática durante o calendário a anual escolar.

Compondo a pesquisa realizada, sequencialmente serão realizadas a observação da realidade com embasamento realizada por meio de um questionário direcionado a docentes que atuam na cidade de Araguari e região; a delimitação da problemática de acordo com o resultado do questionário aplicado; a partir da teorização serão desenvolvidas as hipóteses de soluções e as propostas para aplicação à realidade utilizando métodos distintos referente a cultura indígena e a importância de sua valorização no currículo escolar; por fim apresentar-se-ão as considerações finais e as referências utilizadas na composição deste artigo.

\section{OBSERVAÇÃO DA REALIDADE}

"O conhecimento é um dom concedido por aqueles que se consideram como seus possuidores àqueles que eles consideram que nada sabem" (FREIRE, 1979 , p. 15). Para o autor, alunos são considerados meros depósito de informações, o que distancia, e muito, daqueles que produz conhecimento. Essa prerrogativa coloca em pauta a metodologia de problematização na aplicação da temática indígena pelos professores em sala de aula.

Para a observação da realizada utilizou-se de um instrumento de identificação da adesão das instituições educacionais à Lei 10.639/03. O instrumento intitulado "Questionário - Educação das Relações Étnico-raciais e história e cultura afro- brasileira, africana e indígena" foi aplicado por meio de um formulário on-line distribuído ao mais amplo público de professoras atuantes nas diversas instituições na cidade de Araguari e região através do aplicativo WhatsApp, visto que pandemia da COVID-19 impossibilitou nesta etapa a realização de ações presenciais. As respostas foram coletadas entre os dias 24 e 30 de abril de 2020, tendo como respondentes professoras, sendo suas respostas anônimas. $O$ perfil das respondentes ao questionário corresponde $\mathrm{a}$ :

Faixa etária:

- $60 \%$ entre 20 e 35 anos;

- $10 \%$ entre 36 e 50 anos;

- $\quad 30 \%$ entre 51 e 65 anos.

Sexo:

- $\quad 100 \%$ feminino.

Nível de formação:

- 40\% graduação;

- $40 \%$ especialização;

- $10 \%$ mestrado;

- $10 \%$ magistério.

Atuação em instituições educacionais de que seguimento:

- 20\% públicas municipais;

- 20\% públicas estaduais;

- $60 \%$ instituições Privadas/particulares.

Por meio do formulário questionou-se aos docentes sobre a temática da educação das relações éticoraciais e história e cultura afro-brasileira, africana e indígena e obteve-se dados, que serão citados posteriormente, sobre a realidade atual nas instituições em que atuam, os quais nortearão ações e/ou intervenções para o desenvolvimento e conclusão do presente artigo.

Evidenciou-se que a maioria das professoras possuem a idade entre vinte e trinta e cinco anos, são todas do sexo feminino, possuem graduação e especialização e maioria atuam em instituições privadas. As docentes alegam que os conteúdos e forma a serem abordados em sala de aula é um processo que está em fase de desenvolvimento, porém muito pouco desenvolvido. Verificou-se, também, que metade da porcentagem trabalham os 
valores, conceitos, atitudes e habilidades que levam os estudantes desenvolverem personalidades abertas ao respeito às diferenças e contrárias ao racismo, preconceito e discriminação.

Diante disso, pôde-se destacas a relevância dos professores em se comprometer para criar um clima de valorização da diversidade e respeito às diferenças no ambiente escolar e o ensino da temática de forma lúdica e atrativa para efetividade do conhecimento.

\section{3}

\section{JUSTIFICATIVA}

Buscou-se compreender a educação acerca da temática indígena como uma prática de ensino aprendizagem específica, pautado na cultura indígena, priorizando sua abordagem a partir da realidade, sob uma ótica crítica, rompendo visões do senso comum associadas a este povo.

O maior desafio é o de romper as barreiras colocadas pelo senso comum e pelo preconceito e, assim, pautar-se na educação como um dos instrumentos na eliminação do racismo, promovendo a igualdade social e a construção de novas atitudes e valores (DE SOUSA SANTOS; CHAUÍ, 2016, p. 8).

Nesse sentido, apesar de reconhecer a relevância das leis, ressalta-se que todos os envolvidos, sejam eles professores, movimentos sociais, alunos e instituições, precisam acompanhar sua real aplicabilidade. Com a finalidade de contribuir com esse debate no contexto escolar, este artigo busca analisar a relevância da aprovação de leis na educação escolar brasileira na perspectiva dos aspectos culturais.

A escola é formada por uma população diversificada com grupos, costumes, culturas e crenças diferentes, em que cada qual carrega consigo experiências de vida distintas. É importante discutir e esclarecer ideias equivocadas e enraizadas culturalmente, pois elas impedem a compreensão acerca da sociedade brasileira. Sem que se estabeleça conhecimentos corretos referentes a história indígena, sobre o que de fato aconteceu na relação com os índios, não se pode explicar o Brasil contemporâneo.

As sociedades indígenas constituem uma população sensível da natureza da sociedade, haja vista seus hábitos e a disseminação de conhecimentos passados de forma rudimentar, sendo incompreendida pela sociedade com vieses capitalistas e tecnicistas. A sociedade brasileira se desnuda e se revela no relacionamento com os povos indígenas. Nesse sentido, tentar compreender as sociedades indígenas não é apenas procurar conhecer seres de hábitos diferentes, mas implica conduzir as indagações e reflexões sobre a própria sociedade. (FREIRE, 1979, p. 18)

Observou- se a importância de compreender o tema indígena no ensino fundamental, pois assim se farse-á a valorização e compreensão das culturas indígenas, percebendo suas peculiaridades e diversidades como peças de um rico variado tesouro cultural, que caracteriza a sociedade brasileira como um todo, evidenciando o importante papel dos docentes como protagonistas desse processo para apropriação sobre o conhecimento do país.

\section{PROBLEMA}

A falta de aprofundamento acerca da temática indígena em sala de aula potencializa um relevante problemática para a educação no país e na formação de cidadãos críticos e conhecedores de aspectos históricos que remetem a uma sociedade com tamanha desigualdade. Muitos textos e grupos de pesquisa têm se dedicado a (re)pensar a formação de professores que tenham propriedade sobre as culturas indígenas, assim como a produção de material didático para escolas. (PAIVA, 2017, p. 5)

Relacionado à visão lançada sobre os indígenas e o precário entendimento resultante da limitada produção historiográfica, a produção didática é muito restrita no que tange a história do Brasil, ressaltando que algumas pesquisas acadêmicas ainda colocarem os indígenas em um papel secundário da colonização.

A introdução da história indígena em sala de aula, e nos materiais didáticos, não devem constar coo meros acréscimos no currículo escolar ou na história do Brasil. Os docentes precisam instigar o conhecimento dos alunos e utilizar metodologias atrativas e distintas que potencializem o aprendizado, não somente em datas comemorativas, mas no decorrer do ano, inserindo a abordagem em distintos conteúdos e unidades curriculares. 
Por meio do instrumento de pesquisa aplicado às professoras detectou-se que algumas questões apresentam grande inconformidade com o proposto pelas diretrizes governamentais. As questões de destaque foram:

1. Questão número um: utilização de metodologias distintas utilizadas em sala de aula;

2. Questão número dois: a temática étnico-racial está sempre disponível, com fácil acesso e visibilidade.

Partindo de concretas análises, identificou-se que as problemáticas foco desse artigo buscam responder as indagações:

- Como abordar a diversidade cultural de forma atrativa e lúdica?

- Como desenvolver um clima de valorização da diversidade e respeito às diferenças no ambiente escolar?

A partir dessas indagações alternativas foram levantadas na busca de hipóteses de soluções aos problemas destacados frente às docentes do ensino fundamental nas instituições públicas e particulares da cidade de Araguari/MG.

\section{5}

\section{PONTOS-CHAVE}

O multiculturalismo tem seu principal foco na educação, pois a escola recebe com entusiasmo a ideia de igualdade para todos e de combate à discriminação e ao racismo, sem refletir, muitas vezes, em quais bases este antirracismo foi construído. De forma geral, os países que adotaram as políticas multiculturais elaboraram uma reforma na lei maior (Constituição Federal do Brasil) e, na sequência, direcional a ação para a reforma política educacional dando ênfase ao currículo, ao material didático e à formação dos professores (FAUSTINO, 2006, p. 9).

Algumas práticas de ensino na escola colaboram para o fortalecimento de valores relacionados ao respeito pela diferença e a neutralização do preconceito, inseridos em uma conjuntura que prima pela organização escolar e curricular com base em componentes estéticos, políticos e éticos.
Com isso, professores amparam-se na experiência humana do aprender a conhecer, aprender a fazer, aprender a conviver, aprender a ser. A difusão das práticas relacionadas a temática indígena passa a ser entendida como uma responsabilidade de todos os envolvidos e deve resultar em atitudes que repudiam a discriminação e o preconceito.

Estas propostas foram desenvolvidas pensando na situação atual e na contemplação plena dos conteúdos abordados nas culturas éticos-raciais. Endente-se que os fatores que exercem considerável influência para que o problema exista são:

- Defasagem na formação continuada de docentes no que tange temáticas relacionadas à cultura indígena;

- Escassez de materiais didáticos;

- Ausência de protocolos de combate a situações discriminatórias e racistas nas escolas.

A partir desses pontos-chave buscou-se o aprofundamento teórico para compreensão e apropriação dos conceitos, conteúdos e práticas relacionadas ao tema em questão.

\section{TEORIZAÇÃO}

A fundamentação teórica que propicia um maior embasamento a respeito dos pontos-chave levantados e, consequentemente, conduz às hipóteses de solução para o problema eleito, contou com livros disponíveis em bibliotecas virtuais e artigos científicos contidos em repositórios online.

De forma mais geral, o ensino da cultura afrobrasileira e indígena deve-se ser apresentada no decorrer do ensino escolar, priorizando a interdisciplinaridade. Faz-se relevante destacar que Lei 10.639/03 determina a obrigatoriedade da inclusão do ensino de história e cultura afrobrasileira no ensino fundamental. Já a Lei 11.645/08 atribui as diretrizes e bases da educação nacional e direciona a incorporação no currículo oficial da rede de ensino a obrigatoriedade da temática história e cultura afro-brasileira e indígena.

Diante tais pressupostos, indaga-se: por que uma lei para dar peso de obrigatoriedade para a abordagem desses conteúdos? O quanto é efetiva a existência 
de uma lei que impõe a obrigatoriedade se são pouco os professores preparados para levar adiante esse estudo com a devida abordagem? O ensino da história e da cultura afro-brasileira e indígena nas escolas, prevista pela lei, é o melhor caminho no sentido da educação intercultural? Essas e outras questões são levantadas ao revisitar a temática indígena e sua relação com a escola.

A imagem do índio que é constituída na infância das crianças brasileiras prevalece ao longo de suas vidas, junto aos estereótipos e marcadores sociais impostos, por toda sua trajetória de vida, pois são escassos os contatos com a temática indígena na educação.

\subsection{Defasagem na formação continuada de docentes no que tange temáticas relacionadas à cultura indígena}

Formar professores capazes de lidar com a diversidade é uma tarefa complexa compartilhada entre a secretaria de educação continuada, alfabetização, diversidade e inclusão. Faz-se relevante que os currículos aplicados nas escolas incorporem a temática, tanto nas dimensões do saber local quanto nos aspectos relativos à docência. Desta forma não deve constatar somente como conteúdo na BNCC (Base Nacional Comum Curricular) e sim como oportunidade para rever as práticas docentes na educação regular, aplicadas nas escolas não indígena. Porém, há uma ausência de políticas efetivas para a formação de professores, bem como a escassez de recursos didáticos adequados para a abordagem de professores no que tange a temática.

Esta perspectiva da interculturalidade constitui uma tarefa provocadora para esse grupo de formação continuada de professores, pois é necessário ultrapassar uma visão romântica do diálogo intercultural e enfrentar os conflitos e desafios que supõe." (CANDAU, 2010, p. 32).

Nessa perspectiva intercultural de educação, implica-se mudanças na prática educativa, de modo a respeitar e integrar as diferenças, a desenvolver novas metodologias pedagógicas e a implementar processos mais críticos de formação de educadores que não sejam alheios ao contexto em que estão inseridos. As práticas pedagógicas devem ser realizadas para que esses contextos possam proporcionar processo de formação que possibilitem pensar coletivamente discutir, complementar, ressignificar e dialogar.

Viver uma cultura é conviver com e dentro de um tecido de que somos e criamos, ao mesmo tempo, os fios, o pano, as cores o desenho do bordado e o tecelão. Viver uma cultura é estabelecer em mim e com os meus outros a possibilidade do presente. $A$ cultura configura o mapa da própria possibilidade da vida social. Ela não é a economia e nem o poder em si mesmos, mas o cenário multifacetado e polissêmico em que uma coisa e a outra são possíveis. Ela consiste tanto em valores e imaginários que representam o patrimônio espiritual de um povo, quanto das negociações cotidianas através das quais cada um de nós e todos nós tornamos a vida social possível e significativa. (BRANDÃO, 2002, p. 24)

Sendo assim, considera-se que aprender sobre a cultura indígena, como qualquer outra, é aprender a dialogar com diferentes condições sociais, respeitando suas diferenças, costumes e tradições, saberes, valores e práticas sociais. Conhecer e considerar o velho e o novo contribui para que haja a associação de transformações importantes e profundas na cultura.

\subsection{Escassez de materiais didático}

Entre os diversos meios de se educar, e é na educação formal que se fortalece a aprendizagem. A inclusão de pautas relacionadas à cultura indígena nas escolas colabora para orientação e amparo desse povo presente na sociedade brasileira antes mesmo da colonização.

Para que haja o devido aprofundamento é de extrema importância que os docentes façam uso de materiais didáticos durante a apresentação dos conteúdos para que os alunos possam se apropriar de conhecimentos por meio de informações concretas. $\mathrm{O}$ acevo de materiais didáticos sobre a temática indígena é muito restrito, principalmente nas escolas públicas, partes se deve em virtude da baixa publicação referente a esse tema, mas o fator 
de maior impacto é o baixo interesse das entidades governamentais em oferecer algum tipo de orientação ou capacitação para professores.

O material didático ampliou sua função precípua. Além de transferir os conhecimentos orais a língua escrita tornou-se um instrumento pedagógico que possibilita o de intelectualização e contribui para a formação social e política do indivíduo. O livro instrui, diverte mais acima de tudo prepara para a liberdade. (SOARES, 2009, documento on-line)

É por meio desses materiais didáticos extras que as instituições de ensino desenvolver em seus alunos a percepção de que o aprendizado é uma ação contínua.

Os docentes podem utilizar-se de várias metodologias de ensino para potencializar o ensino e aprendizagem, entre elas cabe destaque a observação da realidade vivida. Esta possibilita uma ampla capacidade de autonomia ao aluno, além de tornar-se um estudo mais dinâmico. Deve-se considerar que a sociedade possui concepções préformadas referente a cultura indígena, tanto crianças como adultos possuem pré-conceitos sem sequer pesquisar e conhecer a história que se desenvolve ao longo do tempo, entre as quais estão as lutas pela igualdade, demarcações territoriais, respeito e até mesmo sobrevivência.

Associar a cultura indígena ao conteúdo que está sendo vivenciado pelos alunos resulta em uma rica prática de aprendizagem, proporcionando o contato com as tradições do país e consequentemente o saber de sua história.

Apesar de singela, a imagem tem consequências perversas, as crianças passam acreditar em "índios" que não existem, A riqueza da diversidade cultural é reduzida a pobreza dos estereótipos. E pior que tudo, produz-se uma generalização que pode facilmente ser transformada em preconceito. A base do preconceito reside na generalização de certos tipos humanos, aos quais se atribuem características negativas. Daí a importância de apresentar e valorizar a ampla variedade de costumes e línguas dos povos indígenas. (TASSINARI, 1998, p. 3)
Deste modo, ao acessar ao material didático, os alunos podem conceber percepções e visões diferentes com conhecimentos amplos e vastos, assim conhecem a história e as razões que culminam nos atuais padrões de esteriotipação desses povos. Os professores assumem o papel de regentes e conduzem a exposição dos conteúdos e as explicações dos temas levantados, facilitando para que os alunos aprendam as etapas históricas que os povos indígenas enfrentaram.

6.3 Ausência de protocolos de combate a situações discriminatórias e racistas nas escolas.

Os aspectos relacionados à questão de gênero que impactam em discriminação social, considerando os aspectos raciais, não são totalmente abarcados pelos discursos dos direitos humanos. É fundamental o papel da escola e da formação de professores na desconstrução do racismo, o que reforça a importância de os profissionais da educação dialogarem frente a Lei 10.639/ 2003.

"A criança e o adolescente gozam de todos os direitos fundamentais inerentes à pessoa humana, sem prejuízo da proteção integral de que trata esta Lei, assegurando-se lhes, por lei ou por outros meios, todas as oportunidades e facilidades, a fim de Ihes facultar o desenvolvimento físico, mental, moral, espiritual e social, em condições de liberdade e dignidade." (ECA, 1990. p.08, apud BURATTO, 2007, p. 11)

Os indígenas são cidadãos brasileiros e estão amparados pela legislação geral do Estatuto da Criança e do Adolescente, lei federal que se dedica a eles em seu artigo $3^{\circ} n^{\circ} 8.069$ de 1990 . Apesar de possui uma legislação com aspectos avançados, muitas ações ainda permanecem apenas na teoria. Assim, acredita-se que a garantia desses direitos seja potencializada por meio da formação continuada dos docentes e profissionais capazes de oferecerem informações e conhecimentos para que a comunidade possa agir, reivindicar e mobilizar a aplicação legal.

Por ser um julgamento preestabelecido, o preconceito médio as relações do sujeito com a sociedade, servindo como um pré-julgamento negativo das pessoas, estereotipando-as a partir de 
conceitos distorcidos sobre suas identidades. (SANTANA, 2005, p. 62)

Em virtude dessa configuração, nota-se que ainda não se tem contemplado uma gama de fatores construtores de identidades e subjetividades presentes na aprendizagem. O reconhecimento da história, línguas, etnicidades, religião, suas particularidades individuais, seu lugar, fazem parte das suas representações culturais de uma nação.

A escola deve ter claro e divulgado os protocolos de combate à discriminação e atitudes racistas, fazendo valer o que a legislação propõe. Esses protocolos devem contemplar a orientação e correção dos agressores, assim como o acolhimento das vítimas, quando houver. As atitudes discriminatórias e racistas devem ser pauta da rotina escolar, tanto com alunos como colaboradores, pais e demais entes da comunidade. Frente a situações de discriminação e racismo deve-se agir prontamente para inibir sua reincidência, primando pela implantação de uma cultura de respeito.

A teorização objetivou a realização da pesquisa teórica e o aprofundamento acerca dos problemas destacados. Com base nos pontos-chave, foi averiguado as necessidades de esforços para que se constitua a formação continuada dos docentes voltada para a abordagem da cultura indígena de uma forma mais interessante e lúdica. A utilização de materiais didáticos sobre a cultura indígena em algumas escolas não é realizada, dificultando o entendimento dos alunos. Desataca-se a ausência de protocolos para dar tratativas a situações discriminatórias e racistas que contemple a comunidade escolar, a família e a sociedade.

Em síntese, constituiu-se na etapa da teorização uma condição básica para a apresentação das hipóteses de solução dadas ao problema eleito para o presente estudo.

\section{HIPÓTESES DE SOLUÇÃO}

Os indígenas são grupos sociais ainda desconhecido pela maior parte dos brasileiros, acarretando a necessidade de implantação de políticas de inclusão, que, para serem bem-sucedidas, precisam de apoio das diversas entidades sociais em prol de melhor entendimento acerca da cultura indígena.

(...) a diversidade sociocultural precisa ser abordada interdisciplinarmente como questão antropológica, filosófica, sociológica e política - porque ela traz consigo a questão de como nós representamos e como representamos os outros, e traz também a tensão entre os saberes historicamente constituídos sobre estes povos e suas próprias narrativas e resistências. Nos últimos anos, diversidade cultural tornou-se uma ideia comum e em torno dela se formalizam leis, diretrizes, princípios. A diversidade, como conceito, está presente na LDB, no Plano Nacional de Educação, nos Parâmetros Curriculares Nacionais, nos projetos político pedagógicos de muitas escolas e Universidades. (SILVA; BONIN, 2006, p. 84)

A reflexão voltada aos aspectos desenvolvidos na teorização, realizada com base na literatura selecionada, possibilitou apresentar alternativas que podem contribuir para a solução do problema estudado. A seguir estão algumas sugestões a serem discutidas e implementadas no âmbito escolar:

- Formação continuada dos professores por meio de encontros formais focados no desenvolvimento de estudos específico que facilitem o conhecimento sobre os povos indígenas, possibilitando uma melhor abordagem ao tratar a temática em sala de aula;

- Elaborar um cronograma de atividades que contemplem os povos indígenas junto às famílias, como feira cultural $e$ exposição culinária;

- Utilização da tecnologia, como o uso de softwares que podem ilustrar o cotidiano dos povos indígenas.

- Realizar atividades específicas com a comunidade escolar, através de curso, seminários, encontro de estudos específicos, vídeos e subsídios didáticos;

- Incentivar professores ao interesse em aprofundar nos estudos sobre os povos indígenas por meio de curso de especialização e extensão.

Ao analisar essas alternativas, identificou-se como possibilidades de aplicação mais adequadas com as condições atuais, ofertar a temática indígena nas capacitações e estudos direcionados aos professores. Através delas poderão ser explorados os pontos destacados por Munduruku (2010): 
Em um mundo cada vez mais conectado, o professor precisa estar atento para não reafirmar impressões que não condizem com a realidade dos povos indígenas, celebrando nossas diferenças e valorizando o respeito. Para tanto, é preciso deixar de lado atividades tradicionais e proporcionar uma reflexão por meio de leituras, músicas e filmes que abordam o cotidiano indígena mais profundamente. (MUNDURUKU, 2010, p. 85)

\section{8 \\ POSSÍVEL APLICAÇÃO À REALIDADE}

Visto que o ensino e a aprendizagem sobre a cultura e os povos indígenas são, em suas naturezas, complexos e norteados por vários aspectos e, a partir da análise das hipóteses de solução, de uma reflexão acerca dos fatores imediatos e das condicionantes maiores, bem como do contexto no qual se encontra o problema em questão, elegeu-se algumas contribuições para a solução do problema apresentado.

Essas contribuições objetivam intervir na realidade de modo a buscar o atendimento às necessidades de se promover uma abordagem mais assertiva referente a cultural indígena na educação, e ainda, viabilizar um resgate aos seus costumes e tradições. Busca-se sensibilizar a população sobre a influências e a importância que, tanto a cultura indígena quanto a africana, têm e tiveram ao longo do tempo em diversos setores da sociedade brasileira.

Promover o crescimento profissional do professor tornou-se necessário e a escola é fundamental nesta consolidação Ihes oferecendo ferramentas necessárias, pois a formação continuada de representa um papel estratégico na qualidade da educação.

A teoria tem fundamental importância na formação dos professores, pois dota-os de diversos pontos de vista para uma atuação contextualizada, proporcionando perspectivas de análise para que os docentes compreendam os contextos sociais histórico-culturais, organizacionais e de si próprios como profissionais. (PIMENTA; GHEDIN, 2005, p. 24).

A teoria se faz necessária para o aprendizado dos professores, contribuindo para a concepção de profissionais atentos aos avanços de suas áreas de atuação e conhecimento acerca de conteúdos mais adequados à realidade de seus alunos. Das hipóteses de soluções apresentadas, sugere-se a elaboração e aplicação de uma formação continuada dos professores com encontros para desenvolver estudos específico, assim os eles poderão conhecer melhor os povos indígenas, culminando em melhores abordagens ao tratarem a temática em sala de aula.

Em virtude da pandemia da COVID-19 e suas consequências de isolamento social, não se fez possível a aplicação da proposta, ficando como uma sugestão para implantação em um momento oportuno.

Essa formação poderá acontecer por meio de encontros com os professores, momentos em que serão convidados a que realizar levantamentos de marcadores da cultura indígena, como a culinária, a língua que ainda é utilizada, vestimentas, religiosidade, remédios naturais e o reconhecimento dos povos indígenas no Brasil. Em seguida serão convidados à apresentar suas pesquisas aos colegas e realizar-se-ão um estudo teórico coletivo de aprofundamento no intuito de conhecer seus o reais sentidos e significados. Desse modo todos poderão compreender melhor a valorização e o respeito da cultura, por sinal tão rica, que esses povos trazem consigo e em suas histórias.

A escola pode investir em atividades como oficinas, workshop, congressos e até seminários para o fomento da temática, sendo incentivados com um clima agradável e documentando cada encontro, além de realizar avaliações constantes e ser flexível, respeitando o ritmo, particularidades e facilidades de cada professor.

\section{CONSIDERAÇÕES FINAIS}

Compreende-se que o assunto tratado na realização desse artigo ainda deve ser explorado de forma contínua com os educadores, indo além dos cursos oferecidos pelas instituições de ensino. Ressalta-se a capacidade de transformar o professor em um empoderador e facilitador de educandos para que a educação étnico-racial seja uma realidade nas escolas, não apenas em datas comemorativas.

Tal experiência permite avaliar que a cultura indígena, atuando como linha norteadora em 
diferentes disciplinas e espaços da escola, contribui efetivamente para que, tanto os alunos como professores, possam conhecer, respeitar e valorizar os povos indígenas, percebendo suas peculiaridades e diversidades, como peças de um rico e variado tesouro da cultura brasileira.

Sendo assim, é preciso discutir e problematizar para desconstruir estigmas consolidados na estruturação da imagem do indígena. Ignorar a existência das sociedades indígena, bem como suas contribuições, seguindo com visões inalterável e cristalizadas no tempo, valorizando a cultura eurocêntrica em detrimento a riqueza cultural trazida por esse povo, representa em uma grande desvalorização da cultura brasileira.

Os professores devem se instrumentalizar e compreendendo quem são os indígenas, ressignificando e reformulando conceitos junto a escola, para avançar nas reflexões em direção à educação intercultural. É relevante ter propriedade para abordar essa temática na escola e fazer com que o país conheça a si próprio, oferecendo aos alunos condições para estarem em contato com suas tradições, buscando sua valorização, promoção e preservação.

Essa é uma temática escolar que requer ser bem aplicada, podendo utilizar recursos distintos oferecidos pela tecnologia, pois é de grande valia retratar e ilustrar a diversidade e inclusão dos grupos étnicos raciais. É notório que os docentes abordam este tema apenas em datas comemorativas específicas, realizando atividades sem apresentar e considerar o contexto histórico em que estão inseridos e a importância dos povos indígenas no Brasil e no mundo. É máster apresentar aos alunos a cultura indígena como um todo, incluindo a culinária, os costumes, a vestimenta, a linguagem e demais aspectos desses povos.

Sabendo-se que pode haver omissão por parte das instituições de ensino, cabe ao corpo docente abrir espaços para as inclusões dessa pauta em sala de aula por meio de projetos no decorrer do ano e vencer o preconceito institucionalizado, além de buscar, de forma mais autônoma, preencher lacunas na sua própria formação.

\section{REFERÊNCIAS}

BRANDÃO. Carlos Rodrigues. A Educação como cultura. Campinas: SP: Mercado das Letras, 2002. Gestão escolar, Ribeirão Preto, p. 1, 10 jun. 2020. Disponível em:

https://escoladainteligencia.com.br/como-abordara-diversidade-cultural-indigena-na-sala-de-aula. Acesso em: 14 jun. 2020.

BURATTO, Lucia Gouvêa. A educação escolar indígena na legislação e os indígenas com necessidades educacionais especiais. Universidade Estadual de Londrina, 2007.

CANDAU, Vera Maria. (Org.). Educação intercultural na América Latina: entre concepções, tensões e propostas. Rio de Janeiro: 7Letras, p. 12-43, 2010. Currículo sem fronteiras, v.12, n.1, p.53-69, 2012.

DE SOUSA SANTOS, Boaventura; CHAUÍ, Marilena. Direitos humanos, democracia e desenvolvimento. Campinas: Cortez Editora, 2016.

FAUSTINO, Rosângela. Política educacional nos anos de 1990: o multiculturalismo e a interculturalidade na educação escolar indígena. 2006. Doutorado em Educação -Universidade Federal de Santa Catarina, Florianópolis, 2006.

FREIRE, Paulo. Educação e mudança. Tradução de Moacir Gadotti e Lilian Lopes Martin. Rio de Janeiro: Paz e Terra, 1979.

GOULART, C. M. A. Letramento e polifonia: um estudo de aspectos discursivos do processo de alfabetização. Revista Brasileira de Educação, São Paulo, n. 18, p. 5-21, set./dez. 2013.

MUNDURUKU, Daniel. O Karaíba: uma história do pré-Brasil. Barueri, SP: Manole, 2010.

PAIVA, Eliane Bezerra. A construção da identidade indígena em fontes de informação. 2017.

PIMENTA, Selma Garrido, GHEDIN, Evandro (Orgs.). Professor reflexivo no Brasil: gênese e crítica de um conceito. 3. ed. São Paulo: Cortez, 2005.

SANTANA, A.O.de História e Conceitos Básicos sobre o Racismo e seus derivados. In: MUNANGA, K.et al. (Org). Superando o racismo na escola. 2.ed. Brasília; Ministério da educação, Secretaria de 
Educação Continuada. Alfabetização e Diversidades, 2005.

SILVA, L. L. M.; OLIVEIRA, L. M. Animar memórias e construir outras narrativas. In WUNDER, A.; NOVAIS, M.; MARQUES, D. Nas dobras do (im)possível: ensaios literários e imagéticos. Campinas, SP: Edições Leitura Crítica, 2017. p. 151161.

SILVA, Rosa Helena Dias da; BONIN, lara. O plural da filosofia da educação: dialogando com outras racionalidades. Temas em filosofia da educação. Manaus: Valer Editora, 2006.

SOARES, Wander. O livro didático e a educação.

Portal Abrelivros. Disponível em:

http://www.abrelivros.org.br/home/index.php/14institucional/palavra-da-diretoria/136-o-livrodidatico-e-a-educacao. Acesso em 02 jun. 2020.

TASSINARI, Antonella M. Sociedades indígenas: introdução ao tema da diversidade cultural, In: LOPES DA SILVA e GRUPIONI (Orgs). A temática indígena na escola novos subsídios para professores de $1^{\circ} \mathrm{e} 2^{\circ}$ graus. 2 ed. São Paulo: MEC: UNESCO, 1998. 